\title{
Application of Oil Palm Wood Flour as Fillers in Polypropylene
}

\author{
M. J. Zaini, ${ }^{*}$ Z. Ismail, M. Y. A. Fuad, and J. Mustafah \\ Plastic Technology Group, Standards and Industrial Research Institute of Malaysia (SIRIM), \\ P.O. Box 7035, 40911 Shah Alam, Malaysia
}

(Received November 29, 1993)

\begin{abstract}
The viability of using oil palm trunk wood flour (OPWF), a by-product of the oil palm industry, as a filler in polypropylene (PP) was studied. The OPWF was compounded into polypropylene using a Brabender thermoplastics mixer and a twin screw compounder. Torque of PP/OPWF composite was compared to that of neat polypropylene. The result showed that the mixing torque of polypropylene increases by adding OPWF filler into it. Test specimens of the PP/OPWF composite at $30 \%$ filter content were prepared by injection moulding, their mechanical properties evaluated and compared to a commercial PP/talc composite. The tensil properties, flexual modulus, impact strength, and melt flow index of the PP/OPWF composite were decreased only by a small margin when compared to those of PP/talc. The PP/OPWF composite, on the other hand, has better heat deflection temperature value than PP/talc. The study shows that OPWF has a good potential to be used as an alternative filter for polypropylene. The OPWF used in this study was not treated with any coupling agent.

KEY WORDS Polypropylene / Oil Palm Wood Flour / Fillers / Compounding / Composite / Mechanical Properties /
\end{abstract}

In 1989, the Malaysian oil palm industry exceeded 1.8 million hectares and yielded about 6 million tonnes of oil. It produced over 22 million tones of by-products which comprises of trunk, fronts, empty bunches, press fruits fibres and shells. As agricultural waste, the amount is expected to increase to over 30 million tonnes by the year $2000 .{ }^{1}$ The cost and easy availability of cellulosic (wood based) fillers is one of the main reasons for their demand as extenders or fillers in polymers. ${ }^{2}$ Likewise, abundance of oil palm cellulosic materials that are readily obtained from these by product provides a new era for industrial exploitation and development. While the use of other type of wood flour in the thermoplastics is well known, oil palm wood flour (OPWF) as a filler or reinforcing agent in thermoplastics has yet to be investigated. It has been shown that incorporation of fillers and reinforcing materials significantly changes various properties of thermoplastics. ${ }^{3-7}$ Typical fillers and reinforcements for polypropylene are glass fibres, glass spheres, talc, asbestos, mica, calcium carbonate, and silica. ${ }^{8}$

In this present study, a relatively new type of wood-based filler is being investigated. The origin of the filler is from trunk of an oil palm tree (Elaeis guineensis). Studies carried out on other wood-based fillers have been reported by a number of workers. ${ }^{9-11}$ Recently, modifications of thermoplastics by cellulose-based fillers are creating considerable interest especially due to more favourable processing effect (being nonabrasive when compared to mineral-filled materials). The purpose of this study was to investigate whether the OPWF has the potential to be used as a filler in polypropylene.

\footnotetext{
* To whom correspondence should be addressed.
} 


\section{EXPERIMENTAL}

\section{Materials}

Homopolymer polypropylene W 101 (Melt index $8 \mathrm{~g}$ per $10 \mathrm{~min}$, density $0.90 \mathrm{~g} \mathrm{~cm}^{-3}$ ) was supplied by The Polyolefin Company (TPC), Singapore. Oil palm wood flour (mesh size no. 250) was prepared by the Palm Oil Research Institute of Malaysia (PORIM). The proximate chemical composition of OPWF filler is given in Table $\mathrm{I}^{12}$ No coupling agent was used in this preliminary studies. A commercial grade of talc filled polypropylene CALP $30 \quad(30 \%$ $\mathrm{PP} /$ talc) was supplied by CALP Corporation.

\section{Preparation of Composite}

Prior to compounding, studies on the mixing behavior of polypropylene and its composites were performed. Mixing were done in a Brabender W 50E mixer at temperature of $190^{\circ} \mathrm{C}$ and the blade speed of $50 \mathrm{rpm}$.

The compounding of polypropylene and oil palm wood flour was carried out in a Brabender DSK 42/7 twin screw extruder. The processing temperatures used were in the range of $170-190^{\circ} \mathrm{C}$. A composite sample with $30 \%$ filler loading was prepared and compounded. The mixtures was fed into the hopper of the extruder, extruded, cooled, and granulated.

The compounded samples were prepared into test specimens by the injection moulding technique. The machine used was a 20-t Battenfeld BA 200 CD Plus machine, with

Table I. Proximate chemical composition of OPWF filler

\begin{tabular}{lr}
\hline Chemical composition & Weight \% \\
\hline Holocellulose & 71.8 \\
Alpha-cellulose & 45.8 \\
Lignin & 22.6 \\
Alcohol-benzene Solubles & 1.2 \\
1\% Alkali Soluble & 19.5 \\
Hot water Solubles & 2.5 \\
Pentosans & 25.9 \\
Ash & 1.63 \\
(On-oven-dry basis) &
\end{tabular}

UNILOG 4000 closed loop control system, at injection pressure of 140 bars. A test specimen mould from Mastermould Inc. was employed to mould dogbone shape tensil test specimens $(165 \times 13 \times 3.2 \mathrm{~mm})$ and rectangular bar impact test pieces $(12.7 \times 3.2 \mathrm{~mm})$.

\section{Testing}

Tensil properties were determined using a Lloyd L1000S Tensil/Compression testing machine. An external extensometer (infrared non-contacting) was used to determine the elongation. The test were conducted at a speed of $5 \mathrm{~mm} / \mathrm{min}$ according to ASTM D638. Results were automatically calculated with the aid of Lloyd tensile test software. A minimum of five specimens were tested for each sample.

Flexural test was conducted using the same Lloyd machine according to ASTM D790-86, Test Method 1, Procedure A, i.e., three-point loading system. The support span was $50 \mathrm{~mm}$ with the loading nose and supports diameter of $20 \mathrm{~mm}$ and $10 \mathrm{~mm}$, respectively. The test was run at a test speed of $2 \mathrm{~mm} / \mathrm{min}$ with a $100 \mathrm{~N}$ load cell.

Izod impact test was performed on a Ceast 6456 Izod pendulum impact tester. Notching was carried out on the impact specimens using Devanport notch cutting apparatus. The test was conducted based on ASTM D256-88.

Melt index of each sample was determined according to ASTM D1238 $\left(230^{\circ} \mathrm{C}\right.$ per $2.16 \mathrm{~kg}$ ) using a Zwick D7900 melt flow indexer. An average of 3 runs was taken for each sample. Heat distortion temperature (HDT) tests were performed using a Davenport Vicat/Heat Distortion Apparatus in accordance to ASTM D648.

The moulded test samples were conditioned at $27^{\circ} \mathrm{C}$ and $65 \% \mathrm{RH}$ for 24 hours in accordance with ISO 291 standard on conditioning and testing atmospheres for tropical countries prior to testing. 


\section{RESULTS AND DISCUSSION}

\section{Mixing Study}

Figure 1 shows a typical mixing curve of polypropylene at $30 \%$ OPWF filter content. Mixing torque is high at the charging of polypropylene and OPWF due to the fact that the mixture is still cold and is in a solid form. The torque gradually decreases as the mixture starts to melt and after some time it levels off.

To compare the mixing energy requirement between neat polypropylene and the 30\% composite, torque after 10 minutes (after loading peak) was noted. Ten minutes was taken as the mixing time at which the torque curve has completely leveled off. PP/OPWF composite has a slightly higher torque than neat polypropylene as shown in Table II. This indicates the processibility of $\mathrm{PP} / \mathrm{OPWF}$ composite is almost the same as neat polypropylene in term of its energy requirement.

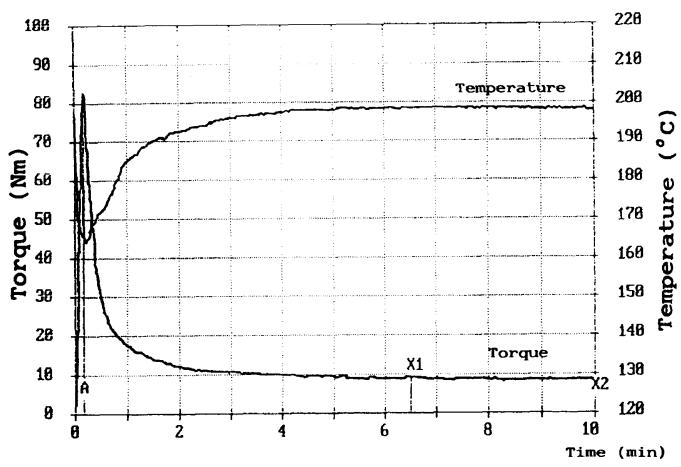

Figure 1. A typical torque-time curve obtained during compounding of OPWF fillers in polypropylene.

Table II. Tests results of polypropylene and its composites

\begin{tabular}{lccc}
\hline \multicolumn{1}{c}{ Properties } & $\begin{array}{c}\text { Polypro- } \\
\text { pylene }\end{array}$ & PP/OPWF & PP/Talc \\
\hline $\begin{array}{c}\text { Mixing torque, Nm } \\
\text { Melt flow index, } \\
\text { g per 10 min }\end{array}$ & 7.0 & 8.8 & 3.7 \\
$\begin{array}{c}\text { Heat distortion } \\
\text { temperature, }{ }^{\circ} \mathrm{C}\end{array}$ & 99 & 130 & 128 \\
\hline
\end{tabular}

\section{Tensile Properties}

Tensile properties of the samples are shown in Figure 2. PP/OPWF composite shows a lower ultimate strength compared with neat polypropylene. As expected, incorporation of particulate fillers into polymer matrix usually decreases the tensile strength of the resultant composites as have been reported by many workers. ${ }^{13,14}$ Existence of fillers in the polymer matrix causes an interruption in stress transfering along the applied force. Moreover, lack of significant interfacial interaction between fillers and polymer matrix aggravate the problem. Irregularly shape fillers as in the case of OPWF filler, are generally not able to support stresses transferred from the polymer, and thus weaken the composite material.4,6 $\mathrm{PP} /$ talc composite appears to have slightly higher tensile strength compared to $\mathrm{PP} / \mathrm{OPWF}$ but the value is still lower than that of the neat popylpropylene. Nevertheless the tensile strength of $\mathrm{PP} / \mathrm{OPWF}$ is not much inferior when compared to that of PP/talc.

Incorporation of OPWF filler into poly-

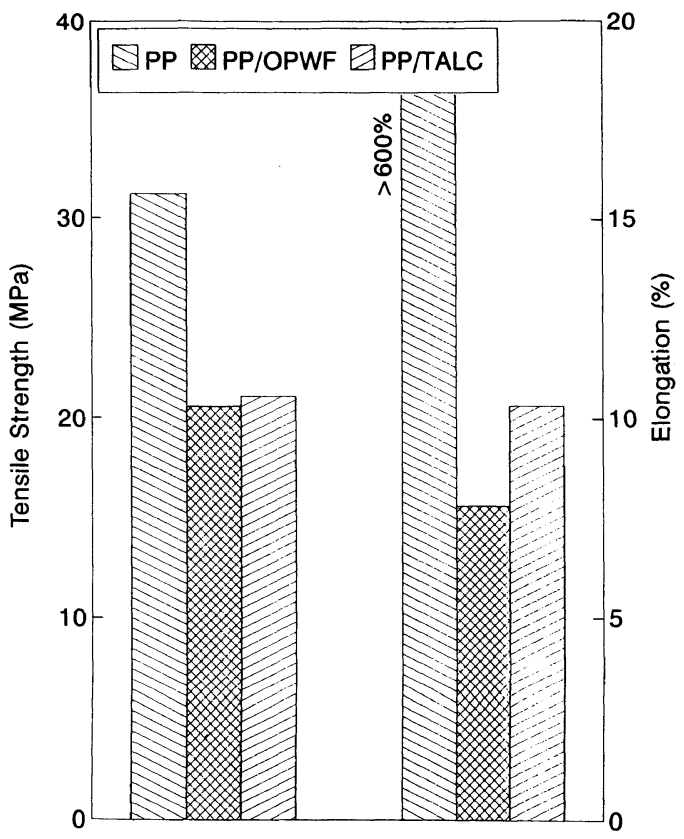

Figure 2. Tensile strength and elongation of polypropylene, PP/OPWF and PP/Talc composites. 


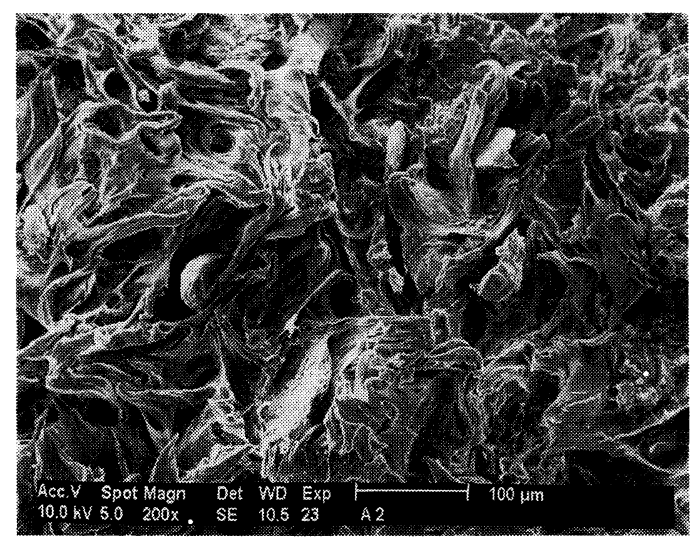

Figure 3. SEM micrograph of PP/OPWF composite at $\times 200$ magnification.

propylene decreases the elongation of the material, as shown in Figure 2. Again, lacking of interfacial adhesion between fillers and polymer matrix causes fracture of the composites at lower degree of elongation. In neat polypropylene the microcracks in the polymer does not travel easily, so higher degree of elongation is expected. Uneven filler particle structure and poor particle dispersion in OPWF as shown in SEM micrograph (Figure 3) may also cause lower elongation at break than $\mathbf{P P} /$ talc.

\section{Flexural Modulus}

Figure 4 shows the comparison between the modulus of the systems under investigation. It shows that by adding filters into the polymer, the flexual modulus, which indicates material stiffness, of the composite will increase. As expected, the PP/OPWF composite shows higher modulus than the neat polypropylene, but the modulus is still lower than that of the commercial $\mathrm{PP} /$ talc composite. There are several factors affecting the modulus of the composite. Those factors are fillter content, modulus and aspect ratio. ${ }^{15}$ Thus, the observation here may be due to the higher modulus of talc compared to the OPWF material.

Equations predicting the modulus of com-

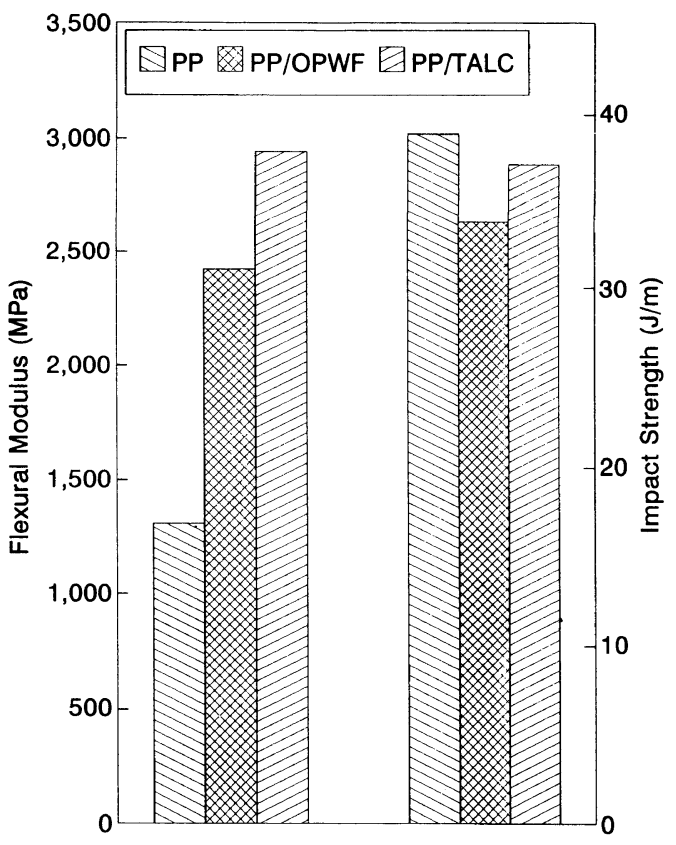

Figure 4. Flexural modulus and impact strength of polypropylene, PP/OPWF and PP/Talc composites.

posites have been proposed by many workers. ${ }^{4}$ The first and simplest form of equation was from Einstein,

$$
E_{\mathrm{R}}=1+2.5 \phi
$$

where $E_{\mathbf{R}}$ is the relative modulus of composite to polymer and $\phi$ is volume fraction of filler. This equation applies only to composites filled with low concentration of noninteractive spheres. To account for interparticle interactions at higher filler concentration, the following equation from Guth is more relevant.

$$
E_{\mathrm{R}}=1+2.5 \phi+B \phi^{2}
$$

where $B$ is usually 14.1 . Lewis and Nielsen has put forward an equation which is more applicable for lower aspect ratio filler. Their equation is as follows,

$$
E_{\mathrm{C}} / E_{\mathrm{p}}=(1+\eta \xi \phi)(1-\eta \Psi \phi)
$$

where

$E_{\mathrm{C}}$ is modulus of composite, $E_{\mathrm{p}}$ is modulus of polymer, $\eta$ is constant related to 
Einstein coefficient, $\xi$ is related to relative moduli of filler and polymer, $\Psi$ is a parameter dependent on the maximum packing fraction of the composite.

The equation covers a number of important conditions exist in composite such as modulus, aspect ratio and packing of fillers in polymer matrix. Theoretical calculation for modulus is not possible at this moment because the value of parameter $\xi$ is not available since modulus of the OPWF filter is not known yet.

\section{Impact Strength}

Izod impact strength of the PP/OPWF composite is lower when compared to that of the neat polypropylene as shown in Figure 4. Nevertheless, the impact strength of PP/OPWF is comparable to the $\mathrm{PP} /$ talc composite. This observation is not unexpected for filled polymers and has been commonly observed. $^{4,16,17}$ This is attribute that poor interfacial adhesion lowers its ability to resist the propagation of cracks may be the reasons attributed to this. ${ }^{17}$

\section{Melt Flow Index}

Table II also records the result of melt flow index (MFI) of the composites. PP/OPWF shows a lower melt flow index value indicating a lower flow compared to the neat polypropylene. This is because the presence of wood flour increases the viscosity of the composite. It was observed that $\mathrm{PP} / \mathrm{OPWF}$ melt has higher melt index value than the $\mathrm{PP} /$ talc. This is another evidence in favour of $\mathrm{PP} / \mathrm{OPWF}$ composite i.e. easier flow when compared to the $\mathrm{PP} /$ talc which results in better processability.

\section{Heat Distortion Temperature (HDT)}

Finally, the HDT test under flexural load was also studied. The test was carried out using a fibre stress of $0.45 \mathrm{MPa}$ at heating rate of $120^{\circ} \mathrm{C} \mathrm{h}^{-1}$ for $0.25 \mathrm{~mm}$ deflection. The results are given in Table II, which shows that the
$\mathrm{PP} / \mathrm{OPWF}$ composite has slightly higher softening temperature than the neat polypropylene.

\section{CONCLUSION}

The findings from this initial study have shown the viability of oil palm wood flour as an alternative filter for thermoplastic composite comparable to a commercial grade of talc filled polypropylene. The tensile strength, elongation at break and impact strength between the two composites are quite close to each other. These mechanical properties of oil palm wood flour may be further improved by using coupling/bonding agents. Subsequent study will make use of various type of coupling agent namely silane and wax-based materials to improve the bonding between the OPWF filler and the polymer matrix. Nevertheless, it should be noted that the method of preparation of samples and composition of wood flour can affect the ultimate properties of the composite.

Acknowledgments. The authors gratefully acknowledge with thanks the staff of Plastics Technology Group, SIRIM, particularly to Rahmad Shukor and Mohd Shalihuddin and also Ridzuan Ramli from Biology Division of PORIM for their support in this research.

\section{REFERENCES}

1. M. Husin, Z. Z. Zawawi, and H. Abdul Halim, Proceedings of the National Symposium on Oil Palm By-products for Agro Based Industries, Malaysia PORIM, Bangi, 1985, p 8.

2. G. R. Lightsey, P. H. Short, and V. K. K. Sinha, Polym. Eng. Sci., 17, 305 (1977).

3. C. D. Han, T. H. Kwack, and H. L. Lou, J. App. Polym. Sci., 29, 2599 (1984).

4. D. M. Bigg, Polym. Comp., 8, 115 (1987).

5. M. Bramuzzo, A. Savadori, and D. Bacci, Polym. Comp., 6, 1 (1985).

6. L. Jilken, G. Malhammar, and R. Selden, Polym. Test., 10, 329 (1991).

7. T. Kawaleski and A. Galeski, J. Appl. Polym. Sci., 32, 2919 (1986).

8. A. Weber, Plast. Rubber Process. Appl., 14, 65 (1990). 
9. R. G. Raj, B. V. Kokta, G. Groleau, and C. Daneault, Plast. Rubber Process Appl., 11, 215 (1989).

10. S. N. Maiti and R. Subrarao, Intern. J. Polymeric Mater., 15, 1 (1991).

11. A. W. Bosshard and H. P. Schlumpf, "Plastics Additives Handbook," R. Gachter and H. Muller, ed., Carl Hanser Verlag, Munich, 1987.

12. L. T. Chew, K. C. Khoo, S. Rahim, and S. Khazirah, Research Pamphlet, 107, 54 (1991).

13. Q. Fu and G. Wang, Polym. Eng. Sci., 32, 94 (1992).
14. S. N. Maiti and B. H. Lopez, J. Appl. Polym. Sci., 44, 353 (1992).

15. A. M. Railey, C. D. Paynter, P. M. McGenity, and J. M. Adams, Plast. Rubber Process. Appl., 14, 85 (1990).

16. M. Y. Ahmad Fuad and J. Mustafah, Intern. J. Polymeric Mater., 19, 75 (1993).

17. G. E. Padawar and N. Beecher, Polym. Eng. Sci., 10, 185 (1970). 